\title{
IoT Based Recipes for Enabling Senior Citizens: Stakeholders Views on How Integration of loT and Web Services Can Enhance Well-Being and Inclusion of Older People
}

\author{
Matteo Zallio \\ Technological University Dublin, matteo.zallio@tudublin.ie \\ Damon Berry \\ Technological University Dublin, damon.berry@tudublin.ie \\ John McGrory \\ Technological University Dublin, john.mcgrory@tudublin.ie
}

Follow this and additional works at: https://arrow.tudublin.ie/engscheleart

Part of the Digital Humanities Commons, Electrical and Electronics Commons, Industrial and Product Design Commons, and the Interdisciplinary Arts and Media Commons

\section{Recommended Citation}

Zallio, M., Berry, D. \& McGrory, J. (2017) IoT Based Recipes for Enabling Senior Citizens: Stakeholders Views on How Integration of IoT and Web Services Can Enhance Well-Being and Inclusion of Older People, AHFE 2017 International Conference on Design for Inclusion, July 17-21, 2017, The Westin Bonaventure Hotel, Los Angeles, California, USA

This Conference Paper is brought to you for free and open access by the School of Electrical and Electronic Engineering at ARROW@TU Dublin. It has been accepted for inclusion in Conference papers by an authorized administrator of ARROW@TU Dublin. For more information, please contact arrow.admin@tudublin.ie, aisling.coyne@tudublin.ie,gerard.connolly@tudublin.ie.

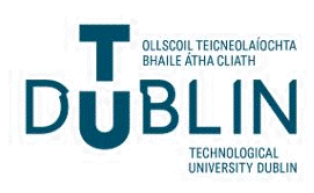


Advances in Intelligent Systems and Computing 587

Giuseppe Di Bucchianico

Pete F. Kercher Editors

Advances in

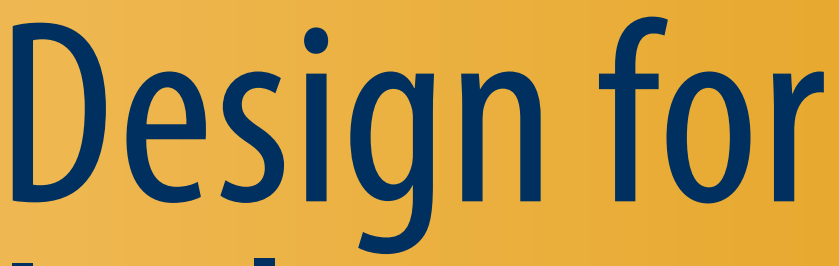

Inclusion

Proceedings of the AHFE 2017

International Conference on Design

for Inclusion, July 17-21, 2017,

The Westin Bonaventure Hotel,

Los Angeles, California, USA

包 Springer 
Giuseppe Di Bucchianico

Pete F. Kercher

Editors

\section{Advances in \\ Design for Inclusion}

Proceedings of the AHFE 2017 International

Conference on Design for Inclusion, July 17-21, 2017, The Westin Bonaventure Hotel, Los Angeles, California, USA

Springer 


\section{Editors}

Giuseppe Di Bucchianico

Dipartimento di Architettura

Università degli Studi

"G.d'Annunzio" Chiet-Pescara

Pescara

Italy
Pete F. Kercher

EIDD - Design for All Europe

Oliveto Lario

Italy

ISSN 2194-5357

ISSN 2194-5365 (electronic)

Advances in Intelligent Systems and Computing

ISBN 978-3-319-60596-8

ISBN 978-3-319-60597-5 (eBook)

DOI 10.1007/978-3-319-60597-5

Library of Congress Control Number: 2017943023

C Springer International Publishing AG 2018

This work is subject to copyright. All rights are reserved by the Publisher, whether the whole or part of the material is concerned, specifically the rights of translation, reprinting, reuse of illustrations, recitation, broadcasting, reproduction on microfilms or in any other physical way, and transmission or information storage and retrieval, electronic adaptation, computer software, or by similar or dissimilar methodology now known or hereafter developed.

The use of general descriptive names, registered names, trademarks, service marks, etc. in this publication does not imply, even in the absence of a specific statement, that such names are exempt from the relevant protective laws and regulations and therefore free for general use.

The publisher, the authors and the editors are safe to assume that the advice and information in this book are believed to be true and accurate at the date of publication. Neither the publisher nor the authors or the editors give a warranty, express or implied, with respect to the material contained herein or for any errors or omissions that may have been made. The publisher remains neutral with regard to jurisdictional claims in published maps and institutional affiliations.

Printed on acid-free paper

This Springer imprint is published by Springer Nature

The registered company is Springer International Publishing AG

The registered company address is: Gewerbestrasse 11, 6330 Cham, Switzerland 


\title{
IoT Based Recipes for Enabling Senior Citizens: Stakeholders Views on How Integration of IoT and Web Services Can Enhance Well-Being and Inclusion of Older People
}

\author{
Matteo Zallio ${ }^{(\bowtie)}$, John McGrory, and Damon Berry \\ School of Electrical and Electronic Engineering, tPOT Research Group, \\ Dublin Institute of Technology, Dublin, Ireland \\ \{matteo.zallio, john.mcgrory, damon. berry\} ddit.ie
}

\begin{abstract}
The main body of research clearly highlights the world's population is rapidly expanding. When this fact is combined with the increase in life longevity due to medical and social advances it alters the demographic balance in relation to age. Hence, the number of people aged 65 and over is constantly increasing. The potential of Smart Technologies and IoT-based devices to improve health has increased rapidly in the last few years and users are now in a position to contribute to the development of the interaction process and need to be properly trained on benefits of using new technologies. IFTTT (If This Then That), Blockly, and other similar tools provide a new perspective on web-based services, and represent an innovative and inclusive instrument to manage small automated tasks between Internet-connected devices by using a simplified interaction approach. The main research question of this work is: how could senior users benefit and adopt smart devices in a proficient way and how can emerging technologies such as automation services enhance safety, health and well-being for people with different abilities? The research method is based on a participatory, Inclusive Design approach, developed through interviews and focus groups, among a restricted number of people of different age and gender, design and usability tests in the further stage. The aim of the work is to make existing technologies more accepted, usable and inclusive for as many people as possible. This goal will be achieved by analysis and by creating a set of interactive and easy to use information and tools for automating different processes, to improve the performance in Activities of Daily Living and increase the connection and socialization between citizens, their family and friends. Applets for Seniors could be seen as a different approach to enable users with different abilities in interacting in a friendly way with new technologies and could be also used as a User Experience facilitator for people who are not familiar with smart devices.
\end{abstract}

Keywords: Design for inclusion · Active assisted living · IoT · Smart environment - Assistive technologies · Universal design . Human factors · Ergonomics 


\section{Introduction}

Nowadays, with the help of medicine and new technologies most people can expect to easily live into their 60s and beyond [1]. In low and middle-income countries, this is largely the result of a significant reduction in mortality at younger ages, particularly during childhood and childbirth, and from infectious diseases [2]. In high-income countries, continuing increases in life expectancy are now mainly due to declining mortality among the older people [3]. The development of new media and technologies is reshaping lifestyles and habits and the way that people live in cities and houses. According to the Administration on Aging, twenty percent of older adult experience difficulty in performing activities of daily living (ADLs), often caused by decreased mobility, stamina and muscle strength; this in turn can lead to social isolation and increased dependence on others for care [4].

Additionally, as citizens age, not only can their physical condition decline, but also their mental and cognitive status could dramatically worsen, even when physical status remains good. It is known that $40 \%$ of older adult experience feelings of loneliness [5] and $20 \%$ suffer from depressive symptoms [6], which can negatively impact on the general condition of their immediate family, relatives and friends [7].

In the last few years, the so called "Digital-age" era, has ushered in a selection of innovative and adaptive tools. Assistive Technology (AT) and Information and Communication Technologies (ICTs), have been proposed as possible resources that may improve the physical and mental situation of older adults and family caregivers [8]. If the associated challenges can be solved, the user should better trust the services that can be safe and used all the time, especially from a data security perspective [9].

In particular, assistive technologies have potential to assist older people with cognitive impairment in different ways: for example, by providing assurance that the senior is safe and is performing necessary daily activities and, if not, alerting caregivers or family members, by helping people compensate for their impairment, assisting and providing aids in the performance of daily activities and by assessing people's cognitive status [10]. On the other side, issues such as usability problems may occur when senior people use new technologies. These problems can happen for many reasons. For example, the so called "technological literacy" barrier that prevents ageing users in benefiting from the use of new devices, User Experience's issues, the lack of a proper visual, audio or tactile feedback that users receive when they interact with touchscreens or physical interfaces and finally usability and ergonomic factors can play a decisive role in user acceptance, especially for such a (through no fault of their own) demanding and challenging group of users.

Many different products, devices and services that are already available on the market provide innovative solutions for people of all ages. These innovations are enabling the growth of new markets but also have a huge potential for developing new tools, objects, appliances, environments and services tailored for different user needs.

Some of these examples can be referred to the latest web-based services such as IFTTT, Blockly, Muzzley, Zapier and many others, that allows users to create conditional statements or similar automatic procedures concerning different tasks. 
One of the most commonly used services in this sector is called IFTTT - If This Then That. IFTTT is a web-service implementation of E-C-A rules [11] with added connectivity to internet of things devices. This novel combination allows "recipes" involving sequences of tasks to be developed in a semi-autonomous way. Nevertheless, IFTTT, released for the first time in 2011, represents an innovative and inclusive service to manage small tasks and processes between Internet-connected devices and applications by using a simply and user-friendly method.

So, taking inspiration from these services combined with their success and aiming to reduce the effort needed by seniors to learn how to use new devices, this research, seeks to identify mainly three investigation topics:

- "How to engage Senior users in using smart technologies in a proficient way and how these emerging technologies can leverage safety, health and well-being of different people?"

- "How can younger family members monitor and assist older members of the family in an unobtrusive way and how can they be connected by using the latest opportunities offered from different interactive services?"

- "Can automation services and tools like IFTTT, Blockly, Zapier, Muzzley and many others, be used as an inclusive, accessible instrument for the daily activities of Senior citizens?"

Considering the increasing complexity that new devices and appliances have displayed in recent years, it is possible to perceive a further attention on the design of interfaces, ergonomics and User Experience design. But there are still some gaps to be covered, such as the "democratization" of technologies for those people suffering from minor disabilities, lack of "technological" literacy, vulnerable users and senior citizens that cannot easily access the wide range of opportunities offered by IoT-based devices. By analysing this changing scenario, the aim of this research is to identify a strategy to make existing technologies more accepted, useful and usable. This is realised by creating a set of interactive, straightforward combinations of information and tools for automating different processes with the goal to improve the performance in Activities of Daily Living and increase the connection and socialization between familiars and friends. One of the final outcomes will be to develop a series of usable and inclusive instructions of different conditional statements or so called "applets" or "recipes" [12], designed to accommodate the needs of Senior users, by using the facilities of common and affordable task automation services, that can simultaneously be accepted and easily used by young family members, carers, relatives.

\section{State of the Art - Background}

\subsection{Smart Technologies and Interactive Devices}

Smart devices are considered to be part of the future of the global economy, especially in relation to the growing ageing population [9]. On the basis of a recent survey from LinkAge society [13] conducted on 1789 users aged 65 and more, it is possible to demonstrate that senior users represent a booming business in the technological 
consumer market. The LinkAge study showed that $41 \%$ of ageing users own a personal computer, while $61 \%$ own a cell phone and $31 \%$ an Internet connection. The generation of so-called "Silver Surfers" have a chance to get closer to the world of technology thanks to the "consumerisation" phenomenon which makes the devices more accessible, affordable and usable [14]. Today, the ageing global population is an ever changing market and is correctly given great consideration by researchers in the fields of Interaction Design, User Experience, New Media and Technologies and also from the technology retail marketers [15]. Sensors and actuators play fundamental roles in our environments and by using them, it is possible to benefit from: systems for controlling comfort of domestic dwellings; systems for monitoring people's health and safety; systems for socialising and edutainment [14].

Generally, houses, transport vehicles and outdoor environments are becoming more equipped with low cost technologies for data transmission such as Wi-Fi, 6LoWPAN Bluetooth SMART, Li-Fi, IR (InfraRed), NFC (Near Field Communication), BTLE (Bluetooth Low Energy) and ZigBee [16], but also sensor tags, Beacons and other small, interactive devices that allow users to access different types of information. Sensors that record, room occupancy, falls, human activity, sleeping patterns, temperature, humidity, light, infrared, presence, smoke or $\mathrm{CO}_{2}$, anti-flood and many others, have the opportunity to be embedded in small unobtrusive devices and deliver many different information. One of the important innovations that characterize all of these products is the massive range of connectivity and the possibility to be remotely controlled with a smartphone, tablet or smartwatch. It is known that one of the main purposes of these devices such as Nest Learning Thermostat, Philips Hue smart lights, and many others, is to automate and simplify some processes inside our houses and work as a small, non-invasive personal assistant that issues reminders about tasks that residents have to do. Most of them are not intended to be open-source systems, that means that they are intended to work in a tightly-constrained context, without sharing data with other devices. But what if all of these devices could share data and information in a more productive way that could be used for other purposes, such as an unobtrusive and anonymous monitoring system, a non-invasive notification service or a reminder for other associated tasks? Simultaneously, the huge potential of all the hidden data could be used in many different ways, such as learning general lessons about domestic activity, without using intrusive systems such as cameras or CCTV systems, but also to send notifications and modify the environment, when dangerous situations or hazards would arise. This idea is analogous to what happens in many contemporary safety systems that are installed in cars, such as the "Pre-Safe" from Mercedes Benz or the "IntelliSafe" from Volvo and "PreSense" from Audi.

\subsection{Web-Based Services for Automating Tasks}

In the past few years, many web-based services grew up and most of them have been developed based on a simple and intuitive principle: link IoT devices to automate sequences of conditional tasks that can be created and modified by users using simple web applications. The potential of these systems is to use the innovation coming from the Internet and especially the Internet of Things, the world of physical devices 
connected to the net, to let objects and commands from users to talk to each other. The principle is simple and can be well explained by using the acronym coined from the first company that released something similar: IFTTT (If This Then That), now changed to IF-DO. These systems work by creating conditional statements that provide different functionalities to link sensors events to actuators actions [17].

IFTTT, like other similar Apps and Web-based services such as: Blockly, Muzzley, Stringify, Zapier, Automate, Cloudwork, Yonomy, Apiant, and many others, is based on the principle of connecting shared information between devices, apps and services from the Internet.

A notable common feature of these systems is that they offer users an accessible way of creating and sharing sequences of tasks, and for IFTTT the increasing number of people using this service, proving the reliability and usefulness of the service provided. According to the latest data, that show an increased number of tools and tasks created with IFTTT (approximately 15 millions of procedures used on a daily basis) [18], webbased facilitators are slowly becoming more and more popular among young and middle age users and the number can only increase as more services and products connect to the different existing platforms.

IFTTT is also breaking down the complexity of coding to the activity of combining images and meta data about images. This is similar to the revolution of changing from MSDOS which required explicit coding knowledge to the GUI of windows where an icon of a file could be placed into a folder thereby symbolically placing the file in that folder. The main function of IFTTT concerns the creation of technology integration recipes or so called "Applets". The Applets are chains of simple conditional statements that develop linkages between different services that are composed by apps and devices that we use every day. The conditional statements have been used in computer science as features of a programming language (if statements) or in active databases (E-C-A rules), which perform different computations or actions depending on a specific programmed condition evaluates to true or false [19].

IFTT is based on the paradigm of the so called "Channels" and "Recipes" and are composed by the sentence If This, Then That. If the system experiences a change in an input stimulus (This), the integrated system will check a condition (Then) in deciding whether to cause some action to happen (That). The Channels represents different services, the Recipes or Applets provide links between channels and are made from Trigger channels and Action channels. For example, if there is a "like" on any picture in Instagram (trigger channel), the photo will be sent to the Dropbox account (action channel). The usage of these services can be performed between many different devices and appliances. IFTTT supports more than 110 services or channels that goes from business, to productivity, to smart home, to education, to fitness. Some of them can be summarized in the following infographic, which has been created in December 2016, by analysing and collecting all the categories of products and services that are available to be used with the IFTTT system. The image shows different field of application where different existing devices, already on the market, can be easily used with the IFTTT tool (Fig. 1). Among these systems and services, there are different conditions that could be analysed, in order to have a clearer view of the potentialities. Some of the existing services have been developed to be used, on a cloud-based environment, some on a stand-alone 
modality, some on a proprietary structure instead of open source and are eligible for different support platforms.

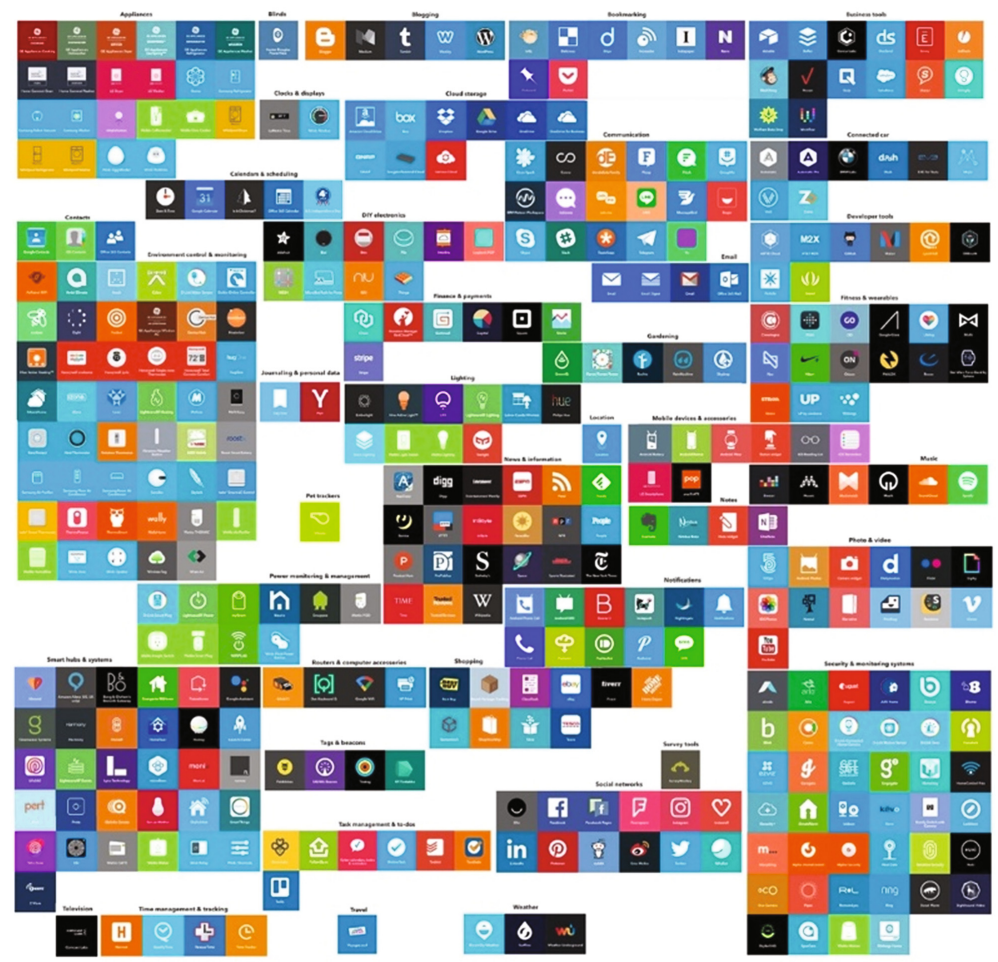

Fig. 1. Infographic of the services supported by IFTTT in December 2016.

From a recent search, of the most recent applications and task automation services on the market, results show that there are at least 15 available services worldwide.

Many aspects differ between task automation services, especially three aspects were considered for the search: where the system stores information and how they can be accessible from the user, whether the system is open source or proprietary, and finally which are the platforms that support the usage of the automation. Finally, it has been seen that systems can be used for different purposes such as business and work, for the home, for marketing and sales and more in general for productivity. The following table provides an overview of the existing platforms, with different services for a wider audience (Table 1).

The interesting aspect is that this selection of systems currently has a wide range of supported apps, where actually it is possible to create thousands and thousands of different recipes for various purposes. The potential of these services is centred on building technology integration recipes, that by merging together information, data taken from sensors and actions performed by actuators it is possible to build a structured and comprehensive pattern of actions and services that will allow people to be more in 
Table 1. Table showing an overview on existing task automation platforms.

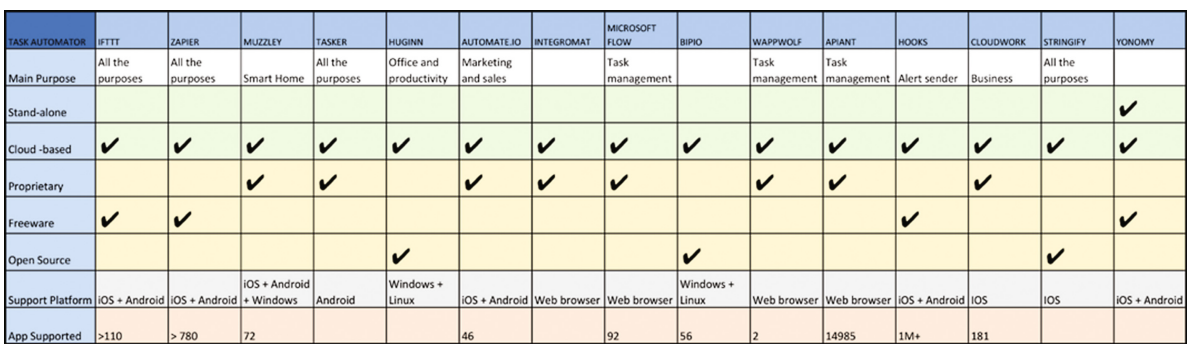

control of their activities, tasks, appointments, but also information concerning health, safety and daily comfort.

\section{Research Methodology}

How can we enable users in an inclusive way? This question drives one of the major challenges that the European commission seeks to have addressed. This challenge is especially focused on those users who suffer from physical or intellectual impairments or those who may simply have some issues in performing certain Activities of Daily Living, through many different calls, part of the Programme Horizon 2020 [20].

Considering the majority of the web-based services for task automation, for reasons mentioned in the previous section, they could be seen as an innovative, but not a wholly disruptive "problem solver" in this space. Nevertheless, they appear to offer a hidden potential that would empower certain group of users in benefits the capacities of IoT-based devices. If we assume that our houses, especially homes designed for people who are going to be ageing over the next years (65 years old or more), could have smart technologies or connected devices, then is possible to think about a new scenario, that allows people to interact in a productive, safer and simple way with different devices. Many recent appliances can be connected to the domestic Wi-Fi router and are enabled to share certain type of information on the cloud. In this sense, task automation, takes some of this information, voluntarily shared by the user and transforms them from sterile data in to a proficient, proactive and useful task or feedback. In order to explore the potential of these systems, the research method has been based on a Participatory Design approach that follows the principles of Inclusive Design [21] and User Centred Design and it has been divided in three different stages. The first stage, already conducted with a focus group, shows the results concerning the usage of specific applets or task automation for senior citizens, investigated with an audience of users and people that are in contact with or work with senior citizens and well know the issues that this group of people may have.

\section{Results: Recipes for Enabling Senior Citizens}

A first pilot study [22], has been conducted with a focus group, composed of a group of 20 assistive technology stakeholders of different age and gender (such as carers, 
designers and engineers, doctors and social caregivers) that are strictly in contact with ageing users and well acquainted with their needs, during the workshops activities of the European Forum on Ambient Assisted Living in St. Gallen, during September 2016. The focus group was prepared with a brief explanation of the concept and then the attention was shifted to opinions, ideas and concepts coming directly from the participants. The majority of participants initially expressed differing opinions in relation to difficulties experiences by senior citizens associated with performing some of the Activities of Daily Living. Activities such as waking up, toileting (use the toilet, have a shower, etc.), dressing, preparing food, communicating with family and friends, watching a TV programme, reading a book, interacting with a tablet or smartphone, taking medicines, hydrating, are some of the most relevant activities and depending of the user can be difficult to perform in a safe, efficient way.

During the focus group, it was noted a number of times, that safety and confidence in personal abilities is an important aspect of the life of ageing user, within their indoor environment. Most of the time users don't want to perform a certain activity/tasks any more on their own or simply they feel uncomfortable in undertaking certain tasks.

For example, different experience considered were:

Ageing people in their mid-sixties, living alone, can be worried about things like: what if a fall event happens? Or what if people become incapacitated and can't reach a phone?

What if some issues occur when people wake up, or occur suddenly when they simply engage in ADL such as low blood pressure, glycaemia and they cannot reach the phone or send an alert?

People want solutions like "set it and forget it" in order to live a normal life, without any intrusive device or system inside their homes. People would like to find light-touch solutions of this type, as many of them are not ageing and don't want to feel like losing their cherished freedom or independence.

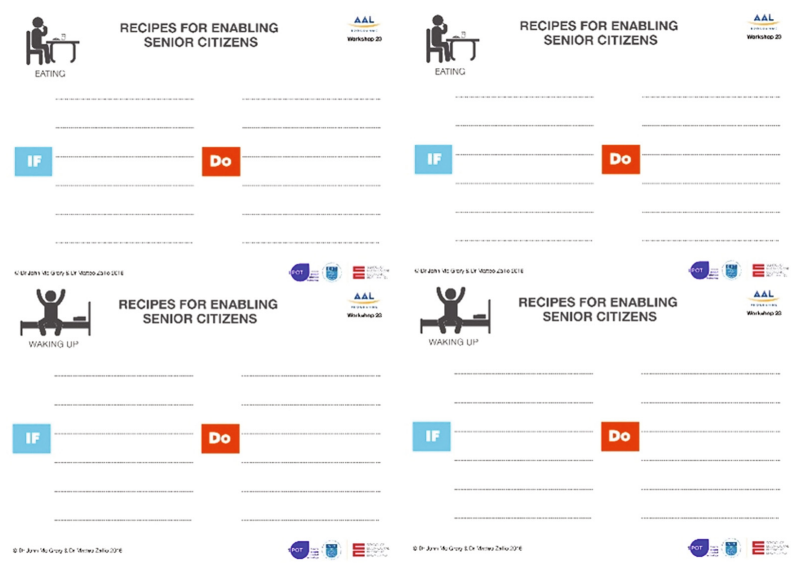

Fig. 2. Examples of cards used for investigating new integration recipes and applets in the focus group. 
In order to identify a restricted number of case studies, useful for designing recipes for senior citizens, the focus group activities have been driven towards completing four different cards that deal with some of the main ADLs previously mentioned (Fig. 2).

Each participant was asked to fill up the cards, with the action that could possibly belong to the so called trigger channel (If) and with another sentence corresponding as an action channel (Do).

This activity represented the first, decisive step in defining the concepts of new IFTTT applets, that could answer the specific needs of the growing ageing population.

For example, if a family member wished to know if the parent or grandparent has woken up and is performing usual ADLs, it is possible to set up a series of applets that are linked to signals coming from smoke detectors, presence or occupancy sensors, smart gas or water meters, that could notify with an email, or message or call on caregiver or familiar's phones, if in the morning the users wake up normally, and started to prepare breakfast or toileting.

During the focus group four different groups of important ADL activities have been shown, where in each of them have been developed different senior-friendly applets.

Group 1: Eating

- If the cooker is off at a certain time then send a message to $\mathrm{x}, \mathrm{y}, \mathrm{z}$ people.

- If the microwave oven is off at a certain time then send a message to $x, y, z$ people.

- If the kettle is off at a certain time then send a message to $\mathrm{x}, \mathrm{y}, \mathrm{z}$ people.

- If the smoke detector in the kitchen registers an alert signal, then turn off the electricity supply.

- If the smoke detector in the kitchen senses no levels of smoke over course of a day, then send an alert/message to $\mathrm{x}, \mathrm{y}, \mathrm{z}$ people.

- If the user's glucose meter detects a low level of sugars, then send a notification to users phone and (with consent of the user) family members.

Group 2: Hydrate - Take medicines

- If I don't turn on the tap in the kitchen for more than $5 \mathrm{~h}$, then send a notification on my phone.

- If I don't open the refrigerator, when at home for more than $5 \mathrm{~h}$, then send a notification on my phone.

- If I don't turn on the kettle at a certain time, then send a reminder with message or email.

- If the pillbox hasn't been opened within a given period, then remind me to take certain medicines.

- At a scheduled time and date, then send me alerts to take certain medicines.

Group 3: Using the toilet - bathroom

- If up to a certain time in a day I don't turn on the light in the toilet, then send an alert to family members.

- If during the night the light in the toilet is turned on more than $\mathrm{x}$ times, then send a notification to family members and users.

- If the water heater is not used for a long time, then send a notification and alert to family members. 
- If the anti-flood sensor detects a risk, then switch off electricity and water supply and send an alert to family members.

\section{Group 4: Waking up}

- If there are no movements (IR doesn't detect anyone) in the house after a certain hour in the morning, then notify caregivers and family members.

- If no cooking appliances have been used up to a certain hour, then notify caregivers and family members.

- If we want to know the record of the sleep patterns, then automatically save the Fitbit sleep logs into a Google spreadsheet.

- If we are still in the bed after a certain hour, then allow Fitbit to send an alert to family members.

- If I remove the phone from the table, send an alert to family members, saying everything is good.

- If I don't login on Facebook/Twitter/Instagram etc. at least once during the day, then send a notification to family members or caregivers.

- If it is a rainy day, then automatically switch on the Philips Hue lights on in orange.

- If it is a sunny day, then automatically switch on the Philips Hue lights on in light yellow.

- If the Nest thermostat hasn't been used for more than $5 \mathrm{~h}$ during the day, then send a notification to family members.

These were some examples, discussed during the focus group, that can be operated thanks to different sensors and actuators, currently present in the market, such as: Nest Learning Thermostat, Philips Hue lights, Fibaro Anti-flood sensor, Belkin Wemo smart plugs, Nest Smoke detector, August smart lock, Fitbit or Apple watch and many other connected devices. In general, it has been observed that monitoring the lifestyle of citizens by using wearable devices like oximeters, blood pressure and heart rate monitor, posture devices and fall prevention systems [23] is one of the main tasks required for people safety, and many of the concept applets have been shaped according to notifications, messages and alerts concerning people's health and safety.

Some of the results of the focus group are interesting because they deal with simple and important activities that may become dangerous depending on the user ability. The early results of the pilot study are helpful in order to build not only a series of triggersactions, based on ADL, but want to shape a new approach in using the potential of task automator services, with the facilities of the latest smart connected devices available.

Another notable feature of the results is the common theme of monitoring users. Many of the individual recipes that deal with user inactivity and possible incapacitation, instead of single stimuli working independently to cause an alert to be sent, they could quite easily be used in an "ADL channel" where inactivity as detected from a statistical combination of water flow sensor, light switch sensor, room occupancy, kettle usage, social network activity.

In general, in the authors opinion, systems such as IFTTT and others, have the potential as intuitive tools that will increase the "technological literacy" of many users that up until today are not interested or not properly trained in benefit from the usage of 
smart devices and prompts a new era of domestic "technological DIY" using IoT devices and customisable web services.

One of the important aspect that came out from the focus group was that Applets for senior citizens can be used as simple task automator, like the existing one, but more important they can provide a series of notifications and feedbacks to primary user (ageing user) and to family members and caregivers. This aspect represents a novelty feature that would be used as an important, but unobtrusive system of alert and notification for all the family, more usable, accepted and easier to set up.

These are just some practical examples of the many previously identified situations that can bring a disruptive series of functions, more suitable for the demanding needs of senior users.

\section{Conclusions and Future Works}

It is known that nowadays many personal devices, such as wearables, smartphones, tablets, or house appliances such as smoke detectors, learning thermostats, smart lighting systems, presence sensors and many others can be connected in the cloud and are supported by many Web based services for task automation. The idea of using different existing smart devices, and linking them with IFTTT protocols or similar tools would enable more people, even if not addicted to technology, to access information and use them in a more productive way. In order to benefit from the potential of all these technologies and to enable Senior citizens to use these facilities in a safe, productive way and to increase the inner level of security at home, the aim of this part of research was to identify a certain number of sample applets that can be easily delivered to an audience of ageing users or weakness users. The adopted strategy is to make existing technologies more accepted, usable and inclusive, by leveraging groups of expert stakeholders to create a set of interactive and easy to use information and tools for automating different processes, to improve the performance in Activities of Daily Living and to increase the connection and socialization between people, family members and friends. This preliminary pilot study highlighted the potential of this research and the impact on inclusivity and on making smart devices usable and acceptable by Senior people depending on their abilities and education.

The future works and stages of research, will have to be conducted by applying the Quality Function Deployment Method, in order to transfer specific needs of a defined group of ageing users in to empirical solutions applicable by using applets designed for enabling senior citizens, family and friends. After this stage is complete, it will be possible to design and develop a set of applets, shaped to answer to the more demanding issues that the majority of senior citizens have.

The final stage of research will be to test the brand-new group of senior-friendly applets, within a various group of ageing people, followed by a redesign and further development, before the final test and validation of usability, inclusivity and affordance of the total system. This will also take in to consideration a development of a library or a specific group of applets that can be released directly on IFTTT web services or similar. 
One of the final results will be to develop a series of usable and inclusive patterns of different Applets, designed to accommodate needs of Senior users, by using common and low cost task facilitator tools, that can be easily used by young family members, carers and relatives. This work is intended to be a new approach in defining which technology is important to be used in our houses and simultaneously seeks to increase the knowledge of smart automation technologies between ageing and Senior users. Applets for Seniors could be seen as a new way to enable users with different abilities in interacting in a friendly and useful way with new technologies and could be also used as a User Experience facilitator for people who are not friendly with smart devices.

\section{References}

1. World Economic and Social Survey 2007: development in an ageing world. United Nations Department of Social and Economic Affairs, New York. Report No. E/2007/50/Rev.1 ST/ESA/314 (2007). http://www.un.org/en/development/desa/policy/wess/wess_archive/ 2007wess.pdf. Accessed 4 Dec 2016

2. Bloom, D.E.: 7 billion and counting. Science 333(6042), 562-569 (2011)

3. Christensen, K., Doblhammer, G., Rau, R., Vaupel, J.W.: Ageing populations: the challenges ahead. Lancet 374(9696), 1196-1208 (2009)

4. Cheek, O., Nikpour, L., Nowlin, H.D.: Aging well with smart technology. Nurs. Adm. Q. 29(4), 329-338 (2005)

5. Weeks, D.J.: A review of loneliness concepts, with particular reference to old age. Int. J. Geriatr. Psychiatry 9(5), 345-355 (1994)

6. Hooyman, N.R., Kiyak, H.A.: Social Gerontology: A Multidisciplinary Perspective, 6th edn. Pearson, Boston (2002)

7. Blazer, D.G.: Depression in late life: review and commentary. J. Gerontol. Med. Sci. 58A(3), 249-265 (2003)

8. Billipp, S.H.: The psychosocial impact of interactive computer use within a vulnerable elderly population: a report on a randomized prospective trial in a home health care setting. Public Health Nurs. 18(2), 138-145 (2001)

9. Zallio, M., Berry, D., Casiddu, N.: Adaptive environments for enabling senior citizens: an holistic assessment tool for housing design and IoT-based technologies. In: Proceedings of IEEE World Forum of Internet of Things, December 2016, Reston VA, USA (2016)

10. Pollack, M.E.: Intelligent technology for an aging population. The use of AI to assist elders with cognitive impairment. AI Mag. 26(2), 9 (2005)

11. Berndtsson, M., Mellin, J.: ECA rules. In: Liu, L., Tamer Özsu, M. (eds.) Encyclopedia of Database Systems, pp. 959-960. Springer, New York (2009)

12. https://ifttt.com/

13. Orlov, L.M.: Technology survey age 65 to 100 - extending technology, past the boomers. In: A Study Sponsored by Linkage (2011)

14. Zallio, M., Casiddu, N.: Lifelong housing design: user feedback evaluation of smart objects and accessible houses for healthy ageing. In: Proceedings of PETRA 2016, 29 June - 01 July 2016, Corfu Island, Greece. Publication rights licensed to ACM 2016 (2016)

15. Furlonger, D.: Maverick research: the future of technology belongs to the "Silver Surfer". In: Gartner Research, 25 September 2013

16. Del Zanna, G., Malavasi, M., Vaccari, G.: Manuale illustrato per la domotica a uso sociale. Tecniche Nuove, Milano (2009) 
17. Meek, B.: Conditional statements. In: Fortran, PL/I and the Algols, pp. 147-150, Macmillan Education, UK (1978)

18. https://bits.blogs.nytimes.com/2014/08/28/with-30-million-more-in-hand-ifttt-looks-to-theinternet-of-things/?_r=0

19. https://ifttt.com/blog/2016/09/welcome-to-the-new-ifttt-blog

20. European Commission. https://ec.europa.eu/programmes/horizon2020/en/h2020-section/ health-demographic-change-and-wellbeing

21. Keates, S., Clarckson, P.J., Harrison, L.A., Robinsons, P.: Towards a practical inclusive design approach. In: CUU 2000 ACM Conference on Universal Usability, 16-17 November 2000, Arlington, VA, USA (2000)

22. Van Teijlingen, E., Hundley, V.: The importance of pilot studies. In: Social Research Update, Issue 35, Winter 2001 University of Surrey (2001)

23. Patel, S., Park, H., Bonato, P., Leighton, C., Rodgers, M.: A review of wearable sensors and systems with application in rehabilitation. J. Neuro Eng. Rehabil. 9, 21 (2012) 